\title{
Presentation of Undescended Testis to a Paediatric Referal Centre in Jos
}

\author{
Andrew Haruna Shitta*, Solomon Danjuma Peter, Ezekiel Dido Dung, Danaan Joseph Shilong, \\ Alexander Femi Ale, Mercy Wakili Isichei, Emmanuel Olorundare 0jo, \\ Michael Ayedima Misauno, Lohfa Bali Chirdan
}

Department of Surgery, Jos University Teaching Hospital, Jos, Nigeria

Email:^shittosis@yahoo.co.uk

How to cite this paper: Shitta, A.H., Peter, S.D., Dung, E.D., Shilong, D.J., Ale, A.F., Isichei, M.W., Ojo, E.O., Misauno, M.A. and Chirdan, L.B. (2020) Presentation of Undescended Testis to a Paediatric Referal Centre in Jos. Open Journal of Pediatrics, 10, 438-446.

https://doi.org/10.4236/ojped.2020.103044

Received: June 12, 2020

Accepted: August 30, 2020

Published: September 2, 2020

Copyright ( 2020 by author(s) and Scientific Research Publishing Inc. This work is licensed under the Creative Commons Attribution International License (CC BY 4.0).

http://creativecommons.org/licenses/by/4.0/

(c) (i) Open Access

\begin{abstract}
Background: Undescended testis is the commonest disorder affecting the male urogenital tract. Late presentation has significant socio-medical impact on the individual's quality of life. Aim: To evaluate the presentation of undescended testis and age at surgery in our centre. Methods: A 9-year retrospective analysis of the clinical records of patients $<18$ years managed for undescended testis in our centre. Results: A total of 73 records were analysed, $58(79.5 \%)$ presented $>1$ year. Median age at presentation was 4 years, range 1 day - 16 years. Males 73 (100\%), only 17 (23.3\%) were referred by health personnel, while $56(76.7 \%)$ self-referred. Commonest site involved was the left 33 (45.2\%), 29 (39.7\%) right and $11(15.1 \%)$ bilateral. There were 13 (17.4\%) who had associated congenital malformations. Hypospadias 7 (53.8\%), isolated micropenis $4(30.8 \%)$ and 1 each $(7.7 \%)$ had myelomeningocele and hernia. Median age at presentation for bilateral involvement was 30 days, with associated hypospadias was 12 days, while those with isolated micropenis was 7.5 years. Median age at surgery for bilateral involvement was 2 years, overall median age at surgery was 4 years. Surgery Findings: Supra-scrotal testis 47, canalicular 25 (34.2\%), and bilateral abdominal 1 (1.4\%). Outcome: Wound infections 4 (5.5\%), scrotal wound breakdown 1, Recurrence 3 and testicular atrophy 1 . Conclusion: Our patients presented very late beyond the recommended age for surgery, evaluating for DSD also contributed to delay in intervention even when these patients presented early. We advocate for early screening at birth, during routine child immunization and school enrollment, with prompt referral.
\end{abstract}

\section{Keywords}

Undescended Testis, Age at Presentation, Orchidopexy 


\section{Introduction}

Undescended testis is the most common disorder affecting the male urogenital tract with profound socio-medical impact on quality of life and individual's reproductive health. Undescended testis is associated with increased risk of infertility, liability to trauma, testicular torsion and cancer, testicular cancer [1]. The incidence of undescended testis varies with age at diagnosis and across geographical regions [2] [3] [4] [5]. The incidence is $3.5 \%$ in newborns, $23 \%$ in preterm or low birth weight babies but declines to around $1 \%$ at 1 year of age [1]. Data from the Nigerian demographic and health survey of 2018, showed only $39 \%$ of live birth took place in a health facility and $43 \%$ assisted by a skilled provider [6]. This implies that over $56 \%$ of new born would have escaped early screening for associated congenital malformations by health workers and therefore the real incidence rate of undescended testis in our environment may be underestimated as some children with undescended testis may never be screened for it. However, there are few studies done to determine its prevalence in Nigeria; a population-based study among nursery/primary school pupils aged 2 - 10 years reported a prevalence of $2.5 \%$ [7]. Another study but hospital-based from south-south region of Nigeria, showed prevalence of $2.9 \%$ and $1.8 \%$ among a cohort of neonates at circumcision and at the ages of 2 years respectively [8].

Testicular development begins intra-abdominally and thereafter descends into the scrotum at birth or shortly after [9]. This can be conveniently divided into two phases. The first phase is the intra-abdominal descent to the inguinal canal. This occurs before the mid-gestation, when the testis remains anchored to the inguinal canal by the gubernaculum which development is enhanced by the release of insulin-like derived growth hormone called calcitonin [9]. The second phase which is the inguinoscrotal phase, is driven by testicular testosterone [9]. Failure in any of these phases leads to the arrest of testicular descend at various levels of the path of descend, resulting in an undescended testis. This may involve either of the testis or both.

In the western world, there are concerted efforts towards early Diagnosis and prompt treatment. Internationally, the most acceptable treatment for undescended testis, is Orchidopexy, as hormonal treatment is found to be associated with poor outcome and long term adverse effect on spermatogenesis [10]. Spontaneous descent is also unreliable as it occurs in only $6.9 \%$ of patients by 1 year of age [11]. There is also significant risk of severe germ cell loss and Leydig cell depletion for each month a testis remains undescended [12]. This has resulted in concerted effort towards early diagnosis and development of treatment guidelines for undescended testis in the western world. The international consensus now is that surgery is advocated as from 6 to 12 months of age to forestall these complications [13] [14] [15] [16] [17].

This consensus is lacking in Africa and Nigeria in particular despite its reproductive health implications.

Undescended testis contributes to the male reproductive health indices. Orc- 
hidopexy within the recommended age of 6 - 12 months is an indirect measure of the paediatric surgical services available [18]. The delay in accessing a paediatric surgical review lies largely on the inability of the primary health care physician or worker who is usually a midwife to follow the international guidelines, as clearly demonstrated in some studies [19] [20]. Many primary health care centres in our country may not be familiar with this guideline because they are not included in the national guidelines.

Procreation is a very important subject in our society and in some communities can be the determining factor in the survival of a marriage. The woman however always bears the blame in most cases of infertility with little or no attention paid to the male counterpart. Male reproductive health in contrast to female reproductive health in our setting has not received the attention it deserves, worst so, the paediatric male reproductive health. This lack of attention could be as a result of ignorance, lack of enlightenment about the magnitude of the problem, lack of interest in being proactive on the part of health personnel or beliefs that exonerates the man therefore less attention. The global health goals of improving maternal and child health care do not include a focus on paediatric male reproductive health [21].

This seeming lack of attention is likely to be as a result of lack of data enough highlighting this burden and how it relates to the child's reproductive health.

It is in view of the paucity of data on the burden of this common male urological tract abnormality and consequent absence of any consensus guidelines on the management in our environment, that we undertook this study with the aim of looking at the pattern of presentation and age at treatment of undescended testis in our centre.

\section{Methods and Materials}

This was a cross sectional, retrospective study of all paediatric patients (below 18 years) who presented to our Centre from January 2011 to December 2019 with undescended testis.

Ethical clearance was duly obtained from the hospital.

Diagnosis of undescended testis was made through clinical examination, radiological imaging (groin ultrasound scans) and in few instances laparoscopy and Karyotyping.

Data was collected from the patients' case notes, ward admission register and operation register of all patients with undescended testis. Information retrieved included patient biodata, age at presentation and subsequent intervention, anatomical side(s) and associated malformation. Multiple entries were eliminated.

All patients within the paediatric age group who presented with undescended testis and were operated within the study period. All those with undescended testis who were not operated within the study period were excluded and those whose data was incomplete. Data was compiled on excel spread sheet, exported into Epi info version and analysed. 
All those presenting without associated congenital anomaly had Orchidopexy within 4 weeks of presentation.

Our reference point for late presentation was any patient that presented beyond the age of 1 year.

Data was compiled on excel spread sheet and exported to Epi info for statistical analysis.

\section{Results}

A total of 73 records were analysed and were all males. Age at presentation was between 1 day -16 years (median $=4$ years). Majority of the patients $20(27.4 \%)$ presented after 1 year of age (Table 1, Figure 1). Only 15 (20.5\%) patients presented within the recommended age of Orchidopexy of 1 year and 27 (38.4\%) presented to our facility before the age of 2 years. While $(19,26 \%)$ were $6-10$ years, $14(19.2 \%)$ were 11 - 16 years (Figure 1). A patient (1.4\%) presented via our EPU at 2 months of age with ipsilateral (right) incarcerated hernia. Reason for presentation was mostly by self-referral $(56,76.3 \%)$ with only $17(23.3 \%)$ referred from other health facilities. Most presentations were unilateral, with involvement of the left in 33 (45.2\%) and right 29 (39.7\%), and 11 (15.1\%) were bilateral (Table 2). All those with bilateral undescended testis had other associated congenital genital abnormality.

There were $13(17.8 \%)$ patients with associated congenital malformations (Figure 2). The most common associated congenital anomaly was Hypospadias with micropenis 7 (53.8\%) followed by isolated micropenis in 4 (30.8\%) patients and myelomeningocele and hernia (incarcerated) in 1 (7.7\%) patient each (Figure 2). Median age at presentation for bilateral involvement was 30 days All those with associated hypospadias presented much earlier with a mean age of 12 days while those who had isolated micropenis, presented much later (irrespective of the site involved) with median age of 7.5 years (ranging between 5 years to 16 years of age). Of those with involvement of the left or right alone, only 3 (9\%) and $4(13.8 \%)$ respectively presented within 1 year of age. Micropenis was found in $1(3.4 \%)$ patient with right undescended testis. Median age at surgery

Table 1. Age of presentation of patients with undescended testis, Jos, Nigeria.

\begin{tabular}{ccc}
\hline Age (Months) & Frequency & Cumulative Freq (\%) \\
\hline $0-6$ & $8(11 \%)$ & $8(11 \%)$ \\
$>6-12$ & $7(9.6 \%)$ & $15(20.5 \%)$ \\
$>12-18$ & $5(6.8 \%)$ & $20(27.4 \%)$ \\
$>18-24$ & $12(16.4 \%)$ & $32(43.8 \%)$ \\
$>24-48$ & $11(15.1 \%)$ & $43(58.9 \%)$ \\
$>48-72$ & $10(13.7 \%)$ & $53(72.6 \%)$ \\
$>72$ & $20(27.4 \%)$ & $73(100 \%)$
\end{tabular}


A. H. Shitta et al.

Table 2. Age at presentation, side involved and type of associated anomaly.

\begin{tabular}{|c|c|c|c|c|c|c|c|}
\hline \multirow{2}{*}{$\begin{array}{c}\text { Age at presentation } \\
\text { Years }\end{array}$} & \multicolumn{3}{|c|}{ Site involved } & \multicolumn{4}{|c|}{ Associated abnormality } \\
\hline & Right & Left & Bilateral & Hypospadias & Micropenis & Myelomeningocele & Hernia \\
\hline$<1$ & 4 & 3 & 8 & 7 & - & 1 & 1 \\
\hline$>1-3$ & 7 & 11 & - & - & - & - & - \\
\hline$>3-5$ & 3 & 3 & 1 & - & 2 & - & - \\
\hline$>5-7$ & 5 & 7 & - & - & - & - & - \\
\hline$>7-9$ & 1 & 1 & - & - & - & - & - \\
\hline$>9-11$ & 3 & 2 & 1 & - & 1 & - & - \\
\hline$>11-13$ & 4 & 6 & - & - & - & - & - \\
\hline$>13-15$ & 2 & - & 1 & - & - & - & - \\
\hline$>15-17$ & - & - & 1 & - & 1 & - & - \\
\hline Total & 29 & 33 & 11 & 7 & 4 & 1 & 1 \\
\hline
\end{tabular}

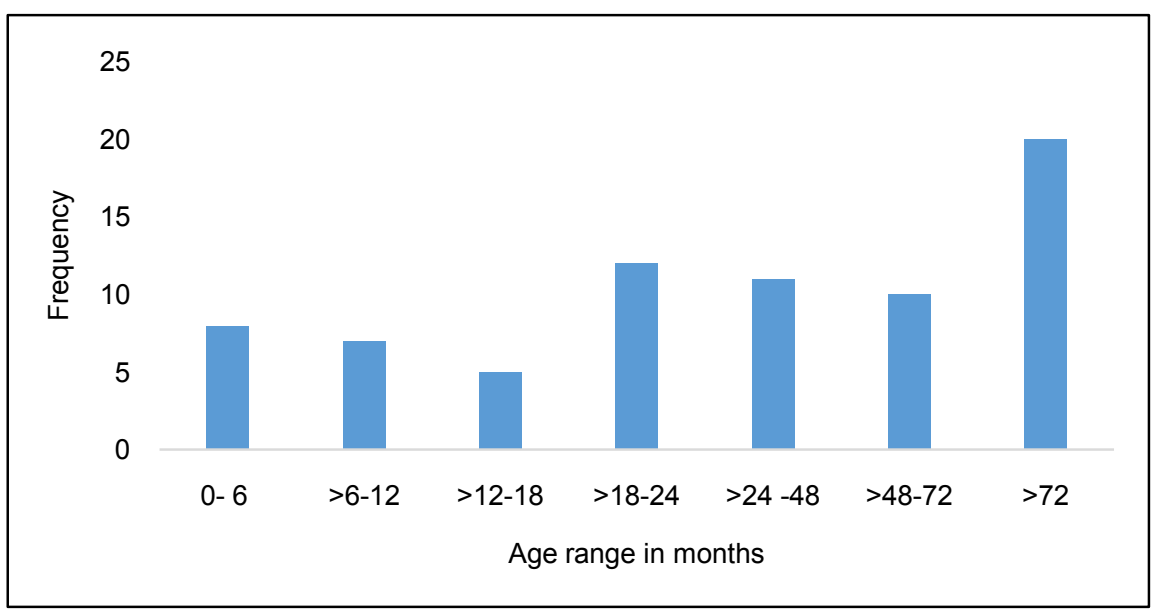

Figure 1. Frequency of age at presentation of undescended testis, Jos 2011-2019.

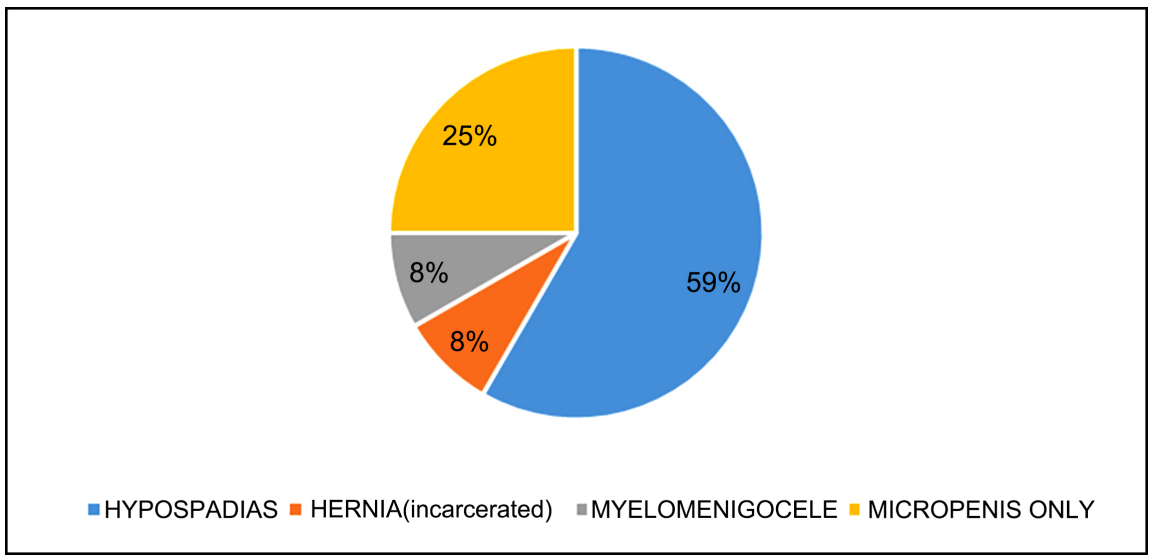

Figure 2. Associated anomaly. 
for bilateral involvement was 2 years. However, the overall median age at surgery was 4 years. At surgery most testes $(47,64.4 \%)$ were found to be supra-scrotal, 25 (34.2\%) canalicular while a patient had bilateral intra-abdominal (1.4\%) testis. Complications included wound infections in 4 (5.5\%) patients out of which 1 had complete scrotal wound breakdown necessitating secondary wound closure. Recurrence was seen in 3 (4.1\%) patients whose initial testes were canalicular after 3 months of follow-up. At 6 months post-Orchidopexy, the right testis in the patient who had bilateral abdominal testes, was noticed to be atrophic thereby, requiring a right orchidectomy.

\section{Discussion}

Our study showed that majority of our patients exhibited delayed presentation with 4 out of every 5 patients presenting beyond the recommended age of one year for Orchidopexy with variation in time of presentation depending on associated malformation(s). The median age of 4 years at presentation is similar to studies done in Zaria (north western Nigeria), Benin (south south), Aba (north eastern Nigeria) and Lagos (south western Nigeria) with median age at presentations and Orchidopexy of 6, 8.3, 6 and 3 years respectively [22] [23] [24] [25]. In Europe and Asia where there exists consensus on management protocols, patients' presentation was relatively early, though the proportion was still far away from the goal of early management. This had been attributed partly to delay in referral pattern by the referring/family physician [26] [27]. A study in Australia found a median age at Orchidopexy of 16.6 months [28]. Even though these studies still show late presentations and surgery, there had been consistent upward trends in the proportions of boy operated within the recommended age group in regions where there exists consensus on the management of undescended testis [26] [28]. Late presentation in our Centre could be attributed to ignorance on this pathology with nearly absent screening and referral protocols to the paediatric surgeon as only a $3^{\text {rd }}$ of our patients were referrals from other health facilities.

The association with hypospadias seemed to be a major determinant of early presentation with a mean age of 12 days. In Australia, a study showed that undescended testis was more likely to be recorded at birth in those with associated congenital anomalies [28]. However, in our study, those with isolated micropenis, presented late (median age of 7.5 years). Early presentation in our patients with associated hypospadias was probably because of the overt appearance of an abnormal phallus that was likely to attract attention. Site (left/right/bilateral) did not seem to influence early presentation.

Acute scrotum/abdomen (torsion, trauma or incarcerated hernia) can complicate an undescended testis [29]. A patient had an emergency presentation due to ipsilateral incarcerated hernia. Commonly reported acute complication of undescended testis is torsion [30] [31]. We had not seen a patient that presented with torsion. 
All our patients had Orchidopexy way beyond the recommended period (median age of 4 years). Must centres with consensus on management also had late surgery, though relatively earlier. This was attributed to delay in referrals [27]. Late surgery at our centre was not surprising, looking at the median age at presentation. Though our patients who had bilateral involvement and associated hypospadias presented early enough, (mean age 12 days) they were still operated late, (mean age at surgery of 2 years). This was because of the need for evaluating for DSD, which took time.

Most of our patients had immediate good outcome. Those that had complications occurred within the first week for wound infection and breakdown. We had few cases of failed Orchidopexy with recurrence among those who presented with canalicular testis in the older age group and testicular atrophy following Orchidopexy in a single patient with bilateral undescended testis. These complications could have occurred as a result of distorted anatomy and difficult dissections during surgery in these older patients who had late intervention.

\section{Conclusion}

Our patients with undescended testis present very late beyond the recommended age for surgery. We found out that evaluating for DSD also contributed to delay in intervention even when these patients present early. It is hoped that this study will contribute to building a consensus on the need for early screening/detection of undescended testis at birth or during routine child immunization by trained health workers and prompt referral to a paediatric surgical Centre for proper management.

\section{Conflicts of Interest}

The authors declare no conflicts of interest regarding the publication of this paper.

\section{References}

[1] Braga, L., Pemberton, J. and Cameron, B. (2012) Cryptorchidism: A Comprehensive Clinical Review. Canadian Urological Association Journal, 11, S26-S32.

[2] Thong, M.-K., Lim, C.-T. and Fatimah, H. (1998) Undescended Testes: Incidence in 1,002 Consecutive Male Infants and Outcome at 1 Year of Age. Pediatric Surgery International, 13, 37-41. https://doi.org/10.1007/s003830050239

[3] Acerini, C.L., Miles, H.L., Dunger, D.B., Ong, K.K. and Hughes, I.A. (2009) The Descriptive Epidemiology of Congenital and Acquired Cryptorchidism in a UK Infant Cohort. Archives of Disease in Childhood, 94, 868-872. https://doi.org/10.1136/adc.2008.150219

[4] Okeke, A. and Osegbe, D. (2001) Prevalence and Characteristics of Cryptorchidism in a Nigerian District. BJU International, 88, 941-945. https://doi.org/10.1046/j.1464-4096.2001.02414.x

[5] Ghirri, P., Ciulli, C., Vuerich, M., Cuttano, A., Faraoni, M., Guerrini, L., et al. (2002) Incidence at Birth and Natural History of Cryptorchidism: A Study of 10,730 Consecutive Male Infants. Journal of Endocrinological Investigation, 25, 709-715. 
https://doi.org/10.1007/BF03345105

[6] Commission NP (2019) Nigeria Demographic and Health Survey 2018: Key Indicators Report. Abuja, Nigeria.

[7] Adeoti, M., Fadiora, S., Oguntola, A., Aderounmu, A., Laosebikan, D. and Adejumobi, O. (2004) Cryptorchidism in a Local Population in Nigeria. West African Journal of Medicine, 23, 62-64. https://doi.org/10.4314/wajm.v23i1.28085

[8] Osifo, D.O. and Osaigbovo, E.O. (2009) The Prevalence, Postnatal Descent, and Complications of Undescended Testes among Children Who Underwent Neonatal Circumcision in Benin City, Nigeria. Journal of Pediatric Surgery, 44, 791-796. https://doi.org/10.4314/wajm.v23i1.28085

[9] Josso, N., Rey, R.A. and Picard, J.-Y. Anti-Müllerian Hormone: A Valuable Addition to the Toolbox of the Pediatric Endocrinologist. International Journal of Endocrinology, 2013, Article ID: 674105. https://doi.org/10.1155/2013/674105

[10] Martin Ritzén, E., Bergh, A., Bjerknes, R., Christiansen, P., Cortes, D., Haugen, S., et al. (2007) Nordic Consensus on Treatment of Undescended Testes. Acta Paediatrica, 96, 638-643. https://doi.org/10.1111/j.1651-2227.2006.00159.x

[11] Wenzler, D.L., Bloom, D.A. and Park, J.M. (2004) What Is the Rate of Spontaneous Testicular Descent in Infants with Cryptorchidism? The Journal of Urology, 171, 849-851. https://doi.org/10.1097/01.ju.0000106100.21225.d7

[12] Tasian, G.E., Hittelman, A.B., Kim, G.E., Disandro, M.J. and Baskin, L.S. (2009) Age at Orchiopexy and Testis Palpability Predict Germ and Leydig Cell Loss: Clinical Predictors of Adverse Histological Features of Cryptorchidism. The Journal of Urology, 182, 704-709. https://doi.org/10.1016/j.juro.2009.04.032

[13] Pettersson, A., Richiardi, L., Nordenskjold, A., Kaijser, M. and Akre, O. (2007) Age at Surgery for Undescended Testis and Risk of Testicular Cancer. New England Journal of Medicine, 356, 1835-1841. https://doi.org/10.1056/NEJMoa067588

[14] Ritzén, E.M. (2008) Undescended Testes: A Consensus on Management. European Journal of Endocrinology, 159, S87-S90. https://doi.org/10.1530/EJE-08-0181

[15] Kolon, T.F., Herndon, C.A., Baker, L.A., Baskin, L.S., Baxter, C.G., Cheng, E.Y., et al. (2014) Evaluation and Treatment of Cryptorchidism: AUA Guideline. The Journal of Urology, 192, 337-345. https://doi.org/10.1016/j.juro.2014.05.005

[16] Chan, E., Wayne, C. and Nasr, A. (2014) Ideal Timing of Orchiopexy: A Systematic Review. Pediatric Surgery International, 30, 87-97. https://doi.org/10.1007/s00383-013-3429-y

[17] Stein, R., Loersch, F. and Younsi, N. (2020) German Guideline on Undescended Testis-What Is Relevant in Daily Routine? Der Urologe Ausg A, 59, 559-564.

[18] Bruijnen, C.J., Vogels, H.D. and Beasley, S.W. (2012) Age at Orchidopexy as an Indicator of the Quality of Regional Child Health Services. Journal of Paediatrics and Child Health, 48, 556-559. https://doi.org/10.1111/j.1440-1754.2011.02202.x

[19] Bradshaw, C.J., Corbet-Burcher, G. and Hitchcock, R. (2014) Age at Orchidopexy in the UK: Has New Evidence Changed Practice? Journal of Pediatric Urology, 10, 758-762. https://doi.org/10.1016/j.jpurol.2013.12.021

[20] Boehme, P., Geis, B., Doerner, J., Wirth, S. and Hensel, K.O. (2018) Shortcomings in the Management of Undescended Testis: Guideline Intention vs Reality and the Underlying Causes-Insights from the Biggest German Cohort. BJU International, 122, 644-653. https://doi.org/10.1111/bju.14171

[21] UNICEF (2008) The State of the World's Children 2009: Maternal and Newborn Health. UNICEF, New York. 
[22] Ameh, E. and Mbibu, H. (2000) Management of Undescended Testes in Children in Zaria, Nigeria. East African Medical Journal, 77, 485-487. https://doi.org/10.4314/eamj.v77i9.46694

[23] David, O.O. and Iyekoretin, E. (2008) Undescended Testes in a Developing Country: A Study of the Management of 71 Patients. African Journal of Paediatric Surgery, 5, 11. https://doi.org/10.4103/0189-6725.41629

[24] Ekpemo, S.C. and Onyearugha, C. (2019) Management of Undescended Testis in Children in Aba Nigeria. International Journal of Clinical Urology, 3, 15-17. https://doi.org/10.11648/j.ijcu.20190301.14

[25] Adesanya, O., Ademuyiwa, A., Elebute, O., Ojewola, R. and Bode, C. (2013) The Undescended Testes in Children: A Prospective Epidemiological Study. East and Central African Journal of Surgery, 18, 45-49.

[26] Hensel, K.O., Caspers, T., Jenke, A.C., Schuler, E. and Wirth, S. (2015) Operative Management of Cryptorchidism: Guidelines and Reality-A 10-Year Observational Analysis of 3587 Cases. BMC Pediatrics, 15, Article No. 116. https://doi.org/10.1186/s12887-015-0429-1

[27] Basalelah, J.H., Alzahrani, A.M., Alshaibani, A.M., Alalyani, N.S., Alsubiani, T.A., Almadi, M.K., et al. (2018) Age at Presentation of Undescended Testicles: A Single-Center Study in Saudi Arabia. Annals of Saudi Medicine, 38, 137-139. https://doi.org/10.5144/0256-4947.2018.137

[28] Schneuer, F.J., Holland, A.J., Pereira, G., Jamieson, S., Bower, C. and Nassar, N. (2016) Age at Surgery and Outcomes of an Undescended Testis. Pediatrics, 137, e20152768. https://doi.org/10.1542/peds.2015-2768

[29] Romero, P.P., Amat, M.C., Santos, L.S., Llobat, T.E., Benlloch, M.M., Paricio, J.T., et al. (1995) Necrosis of Undescended Testis Caused by Incarcerated Inguino-Scrotal Hernia in a Newborn. Actas Urologicas Espanolas, 19, 159-165.

[30] Naouar, S., Braiek, S. and El Kamel, R. (2017) Testicular Torsion in Undescended Testis: A Persistent Challenge. Asian Journal of Urology, 4, 111-115. https://doi.org/10.1016/j.ajur.2016.05.007

[31] Schultz, K.E. and Walker, J. (1984) Testicular Torsion in Undescended Testes. Annals of Emergency Medicine, 13, 567-569. https://doi.org/10.1016/S0196-0644(84)80535-1 